\title{
Onygenalean Fungi as Major Human and Animal Pathogens
}

\author{
Vishnu Chaturvedi · G. Sybren de Hoog
}

Published online: 30 January 2020

(C) Springer Nature B.V. 2020

\begin{abstract}
During the last two decades, many onygenalean pathogens were discovered, redefined, or reclassified from existing taxa into clusters of microspecies, among which the original genotypes often appeared to be uncommon and exceptional. The impact of these developments on the diagnosis and treatment of fungal diseases remains to be determined in most instances. This exciting collection of invited articles provides a full flavor of ongoing changes in the knowledge about taxonomy, genetics, ecology, epidemiology, and clinical spectra of human and animal pathogens classified in the order Onygenales. Recent developments have set the stage for an ambitious translational research agenda. Diagnostic mycology laboratories now need MALDI-TOF-MS spectra, PCR probes, and other specific tools to assist them in the rapid diagnosis of new species. Similarly, an educational set of type materials of new species needs to be readily available for enhanced expertise among the
\end{abstract}

V. Chaturvedi

Mycology Laboratory, Wadsworth Center, New York

State Department of Health, Albany, NY 12208, USA

G. S. de Hoog ( $\square)$

Westerdijk Fungal Biodiversity Institute, Utrecht, The Netherlands

e-mail: Sybren.deHoog@radboudumc.nl

\section{G. S. de Hoog}

Centre of Expertise in Mycology, Radboud University Medical Centre/Canisius Wilhelmina Hospital, Nijmegen, The Netherlands wider medical mycology community. As several new species were discovered retrospectively, it is crucial to expand the re-sampling to other fungal culture collections and archived paraffin tissues. Finally, clinical and laboratory investigations are needed to get an accurate assessment of the prevalence and impact of new pathogens as the cause of major fungal diseases.

Since the early 1990s, relationships among members of the fungal kingdom have undergone critical reshuffling on the basis of ribosomal DNA data, and recognition of molecular cryptic species within the established pathogenic members of the Onygenales using multilocus sequencing [1-5]. Between 2000 and 2019, many onygenalean pathogens were discovered, redefined, or re-classified from existing taxa [6-15]. Long gone are the days when primary dimorphic pathogens could be counted on five fingers of one's hand. Today, many of them have fallen apart into clusters of micro-species, among which the original genotypes often appeared to be uncommon and exceptional $[8,16]$. Although new discoveries are exciting, their impact on the diagnosis and treatment of fungal diseases remains to be determined in most instances. We present an exciting collection of invited articles that provide a full flavor of ongoing changes in the knowledge about taxonomy, genetics, ecology, epidemiology, and clinical spectra of human and animal pathogens classified in the order Onygenales. 
We also summarize some crucial information about the newly recognized dimorphic pathogens in Figs. 1, 2 and Table 1.

The first article in this collection involves a unique genetic analysis of ninety-three strains from forty-nine fungal species of Onygenales [17]. Unlike ribosomal or other common structural genes, the authors use PRP8 intein (internal protein) inserted in the Prp8 (pre-mRNA processing) gene. Nearly $92 \%$ of Onygenales analyzed have PRP8 intein, although the size varies from 494 to $1798 \mathrm{bp}$. The phylogeny of PRP8 intein fully recapitulates Onygenales phylogeny as constructed with classical genetic markers and with whole-genome sequences. Garces et al. [17] have provided a valuable tool to investigate the 'switch' between the saprobic-pathogenic lifestyles of many fungal pathogens in Onygenales.

The last few years have seen a remarkable makeover of recognized genera and species of dermatophytes. The polyphasic re-appraisal of the taxonomy and nomenclature is based upon morphological, genetic, and physiological characteristics. An earlier article in Mycopathologia by de Hoog et al. [9] provided an essential update of the taxonomic status of the members of Arthrodermataceae comprising the most common fungal pathogens of hair, nail, and skin. In the current issue, Dukik and colleagues focus on genus Nannizzia in the family Arthrodermataceae [18]. Thirteen species, including two new species $N$. lorica and $N$. polymorpha, are proposed, the latter being associated with a human skin lesion. This study

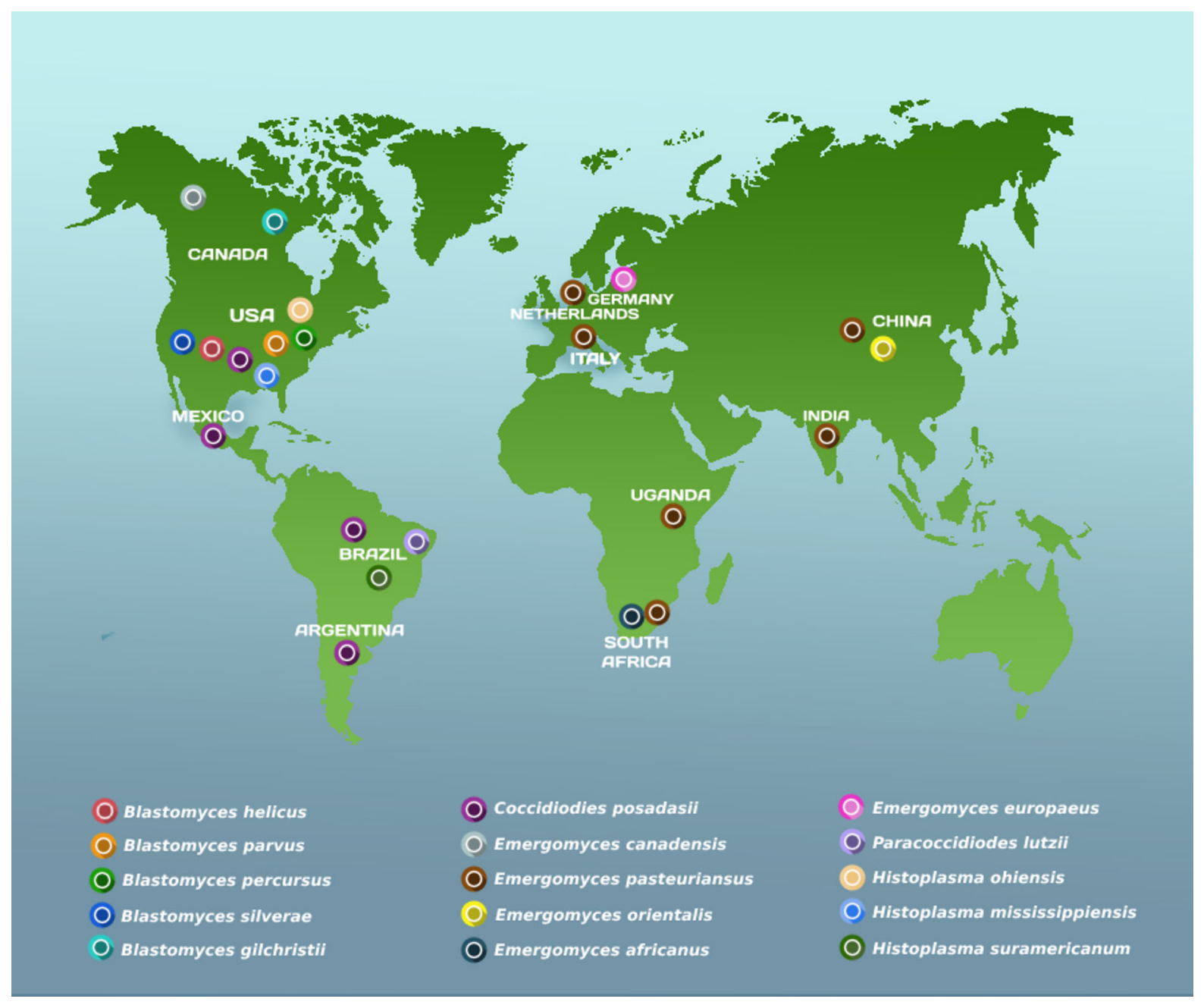

Fig. 1 Geographic distribution of notable primary dimorphic pathogenic fungi described in the last two decades 


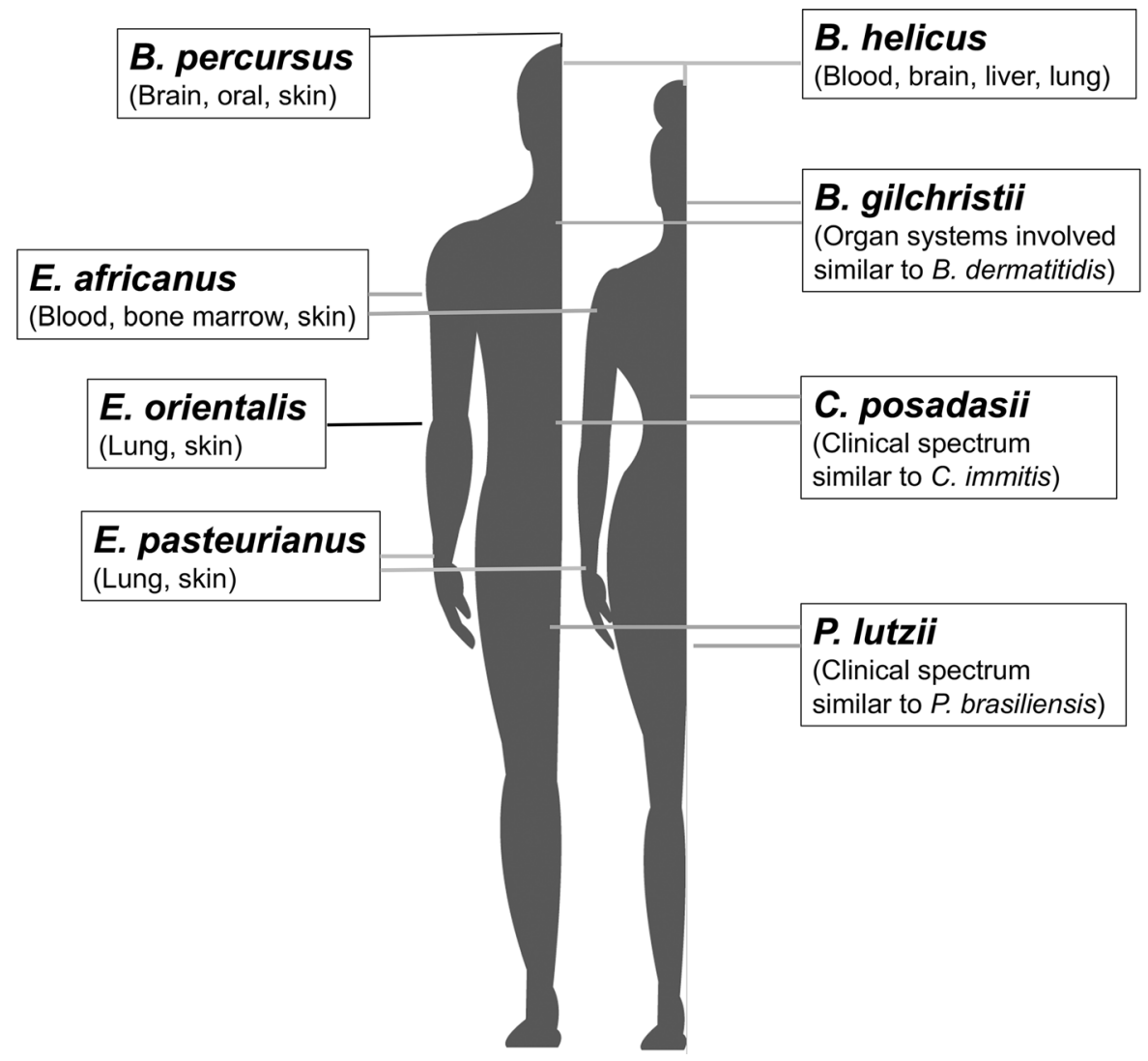

Fig. 2 Body sites and gender distribution of notable new primary dimorphic pathogenic fungi

is a timely update, as the genus name Nannizzia was earlier reserved for the description of the sexual states. With a recent consensus on 'One Fungus - One Name,' the readers will find valuable keys and tools for identification of Nannizzia species irrespective of sexual/asexual forms. Notably, polyphasic approaches recapitulate the established ecological association of Nannizzia species with coat fur of different mammals. Dukik et al. [18] also set the stage for additional investigations if there are other Nannizzia species, not yet identified or misidentified in the past that cause human disease and their relationship to other zoophilic species in this genus. Packeu et al. [19] deploy a polyphasic approach to explore true lineages in the Trichophyton rubrum complex. This task has an essential bearing on routine diagnostic practices and also on epidemiological investigations of dermatophytic infections. Eighty-one well-characterized isolates were studied for their morphology and physiology, ITS-Bt2 multilocus sequence analysis, and a custom-made MALDI-TOF-MS database. The authors discovered characteristic phenotypes of four distinct lineages: $T$. violaceum, T. rubrum, T. soudanense, and T. yaoundei. MALDI-TOF-MS allowed reliable identification of four species with log score (LS) $\geq 1.70$.

Why do soil-dwelling dermatophytes, and to some extent, their zoophilic siblings mate sexually, but this trait is absent in the anthropophilic species? Why does one mating type predominate in anthropophilic dermatophytes? Metin and Heitman [20] address these and other profound questions in their comprehensive review of dual sexuality in dermatophytes. The authors provide a balanced summary of existing literature on sexuality in human pathogenic fungi. Several fitness benefits could accrue for the clonal populations of anthropophilic dermatophytes. Does this super-specialization come with evolutionary disadvantages such as no intermixing of genetic traits? The spontaneous demonstration of the sexual form in the geophilic fungi in keratin-rich soil suggests a requirement for a conducive environment. As the 
Table 1 Diagnostic features of notable primary dimorphic pathogenic fungi described or re-classified in the last two decades

\begin{tabular}{|c|c|c|c|c|c|c|c|}
\hline New species & $\begin{array}{l}\text { Distinct } \\
\text { morphology }\end{array}$ & $\begin{array}{l}\text { Unique ITS } \\
\text { sequence }\end{array}$ & $\begin{array}{l}\text { MALDI-TOF- } \\
\text { MS spectra }\end{array}$ & $\begin{array}{l}\text { Real-time } \\
\text { PCR/ } \\
\text { biomarkers }\end{array}$ & $\begin{array}{l}\text { Antifungal test } \\
\text { (No. isolates) }\end{array}$ & Other hosts & Refs \\
\hline $\begin{array}{c}\text { Blastomyces } \\
\text { gilchristii }\end{array}$ & None & Yes & NA & NA & No & NA & [8] \\
\hline $\begin{array}{l}\text { Blastomyces } \\
\text { helicus }\end{array}$ & Yes & Yes & NA & NA & Yes (1) & Cat, Dog & {$[10]$} \\
\hline $\begin{array}{l}\text { Blastomyces } \\
\text { parvus }\end{array}$ & None & Yes & NA & NA & $\begin{array}{l}\text { Yes }(2, \text { non- } \\
\text { human) }\end{array}$ & $\begin{array}{l}\text { Rodent, } \\
\text { Otter, } \\
\text { Weasel }\end{array}$ & {$[11,30,34]$} \\
\hline $\begin{array}{c}\text { Blastomyces } \\
\text { percursus }\end{array}$ & None & Yes & NA & NA & Yes (1) & & {$[11,12,34]$} \\
\hline $\begin{array}{l}\text { Blastomyces } \\
\text { silverae }\end{array}$ & None & Yes & NA & NA & $\begin{array}{l}\text { Yes (3, non- } \\
\text { human) }\end{array}$ & Weasel & [11] \\
\hline $\begin{array}{c}\text { Emergomyces } \\
\text { africanus }\end{array}$ & & & & & & & {$[34]$} \\
\hline $\begin{array}{c}\text { Emergomyces } \\
\text { canadensis }\end{array}$ & & & & & & & [34] \\
\hline $\begin{array}{c}\text { Emergomyces } \\
\text { orientalis }\end{array}$ & Yes & Yes & No & No & Yes (1) & & {$[13,34]$} \\
\hline $\begin{array}{c}\text { Emergomyces } \\
\text { pasteurianus }\end{array}$ & & & & & & & {$[34]$} \\
\hline $\begin{array}{l}\text { Paracoccidioides } \\
\quad \text { lutzii }\end{array}$ & Yes & Yes & Yes & No & No & NA & {$[7,35]$} \\
\hline $\begin{array}{c}\text { Coccidioides } \\
\text { posadasii }\end{array}$ & No & No & No & Yes & Yes & & {$[6,36]$} \\
\hline
\end{tabular}

NA not available

laboratory conditions do not fully mimic nature, it is difficult to conclude if the anthropophilic dermatophytes are truly asexual. Experimental approaches, successful with other pathogenic fungi, are likely to help investigate if anthropophilic dermatophytes have lost all ability to mate, rarely mate under rigorous recreation of unique natural conditions, or undergo other genetic phenomena such as mitotic recombination [20]. There is an urgency to these studies to understand if dermatophytes are prone to future extinction, or continue to evolve to acquire more virulent forms or antifungal resistance. There has been an alarming increase in primary resistance to terbinafine in T. rubrum, first reported from India. Are these reports harbingers of the global emergence of antifungal-resistant $T$. rubrum analogous to the conditions for Candida auris epidemic? Liu and colleagues share an impressive state-of-the-art whole-genome analysis of antifungal resistance in Trichophyton rubrum [21]. The authors address many relevant questions by
Illumina sequencing of genomes of 48 geographically distinct isolates. The assembled genomes were scored for high-quality single nucleotide polymorphisms (SNPs), which were then used for further population analysis and association mapping. Importantly, a strong association was found between SNPs in the TERG_08871 gene and voriconazole resistance. The authors did not find any unique association among $T$. rubrum MAT1-1 isolates from different geographic locations. The authors have set the conditions and preliminary databases for future genome-wide association studies (GWAS) to understand genetic drivers of antifungal resistance in T. rubrum and other dermatophytes [21]. Kaplan and colleagues described their survey of keratin-degrading gene families in fungalysins (MEP) and subtilisins (SUB) in anthropophilic Trichophyton rubrum and zoophilic $T$. benhamiae and Microsporum canis [22]. The PCRbased survey was conducted with 97 well-characterized isolates. Trichophyton rubrum displayed a robust 
keratin-degradation apparatus in the form of multicopy MEP genes (MEP1, MEP2, MEP3, MEP4, and MEP5) and SUB genes (SUB1, SUB 2, SUB3, SUB4, SUB5, SUB6, and SUB7); SUB1 and SUB6 were rare in the test isolates. Microsporum canis remarkably lacked SUB4, SUB5, SUB6, and SUB7. Future gene expression and proteomic analyses will help delineate the relative roles of keratin-degradation genes as virulence factors for dermatophytes.

The fungal forays were a well-known fun pursuit by the mycologists to assess the occurrence and distribution of unknown fungi in nature. In a modern twist of the foray, Sharma and Shouche conducted systematic sampling over a large geographic area in western India to estimate the prevalence of onygenalean fungi [23]. They found that 551 of 578 samples from keratin-rich habits were positive, comprising 17 genera and 66 species. The authors successfully expanded the diversity of Onygenales by the discovery of three novel taxa, Canomyces reticulatus gen. et sp. nov, Ctenomyces indicus sp. nov, and Currahmyces indicus gen. et sp. nov. Their systematic and selective sampling has an important bearing on future geographic surveys as global distribution of onygenalean fungi remains to be defined, including many undescribed taxa.

Coccidioides immitis and C. posadasii are important primary pathogens causing respiratory and systemic coccidioidomycosis (Valley Fever, VF) in the Americas. Despite tens of thousands of new infections yearly, the natural habitats of these pathogens remain elusive in highly endemic zones in the US southwest and California. This knowledge-gap hampers disease control and prevention efforts and sometimes leads to occupationally exposed outbreaks. A team led by Bridget Barker presents results from a natural survey in Arizona. Five sites were sampled at different time intervals using two different Coccidioides qPCR assays and an assay for mammalian DNA [24]. Onehundred five of 456 soil samples tested positive for Coccidioides spp. Most positive samples came from animal burrows, long suspected to harbor the fungus. DNA from seven different mammal species was found at the fungus-positive sites. These results confirm the wide-spread distribution of Coccidioides spp. in Arizona in animal burrows in geographic locations with reported high or low incidence of human disease. Hainsworth and colleagues describe a unique surveillance approach for the toenail dermatophytes from Australia [25]. The authors collected nail dust bags from podiatric physicians' offices from four different geographic areas. Twenty-two of 32 samples tested positive, yielding 148 ITS sequences positive for dermatophytes. Trichophyton interdigitale was the dominant species with 125 isolates. Notably, only one isolate of T. rubrum was found in the survey. The authors further delineated single nucleotide polymorphism (SNP)-ITS genotypes. Genotype 1 of $T$. interdigitale was predominant in all four geographical regions. Histoplasma capsulatum has a well-defined sexual state, demonstrable in the laboratory by mating between compatible $(+)$ and $(-)$ strains, represented by MAT1 locus idiomorphs MAT1-1 or MAT1-2. Daneri and Mujica set out to survey distribution of mating types in H. capsulatum isolates from Argentina [26]. The authors used yeast forms of the fungus for their PCR-based survey and also confirmed the identity of amplicons by selective sequencing. Among 49 isolates, a skewed distribution of mating types was detected with the predominance of MAT1-1, which was also found in the sole soil isolate. The significance of these findings await further study since other investigators have found MAT1-2 strains switch more readily from mycelial to the yeast form. Guerra and colleagues reviewed forty reports of multiple Histoplasma infections in Brazil since 1946 [27]. A confirmatory diagnosis of histoplasmosis was available in $88 \%$ of the cases. A little over half of these reports suggested exposure to the cave environment, which has a strong association with histoplasmosis. Males were twice as likely to be afflicted as females, and $50 \%$ of all outbreaks were reported from Rio de Janeiro. The highest number of cases in the early eighties mirrored the HIV pandemic. The authors suggest several public health measures to prevent exposure to known risk areas for histoplasmosis.

The recent taxonomic revisions of dermatophytes are driven by robust polyphasic approaches and rooted in the 'One Fungus - One Name' principle. As new taxonomic systems take hold, laboratory scientists and physicians will need a retooling of their tools and vocabulary for a more accurate description of dermatophyte infections. An unanticipated impact of this wholesome revision is highlighted in the article by Baert and colleagues [28]. The authors represent the highly regarded BCCM/IHEM Collection in Brussels, Belgium. They carried out a detailed analysis of 688 reference strains in their collection by multilocus sequencing of ITS and $\beta$-tubulin genes. The efforts 
resulted in re-classification of several genera with overall entries consolidated under fewer taxonomic units. The authors also identified the need for a more extensive multilocus gene set to delineate all dermatophytes in their collection [28]. Trichophyton tonsurans causes human dermatophytosis, while $T$. equinum is appropriately named as the causal agent of equine dermatophytosis. Human isolates of T. equinum, and horse isolates of T. tonsurans, are reported occasionally. Also, both pathogens are indistinguishable from each other when tested by the standard morphological and physiological tests available in the fungal diagnostic laboratories. Therefore, we need to find out if these two fungi represent distinct species or just one species with distinct populations restricted to humans and horses? Kandemir et al. [29] have started on a promising search for answers to these longstanding questions by a polyphasic analysis of 67 reference isolates. The authors discovered $T$. tonsurans grew exclusively on Trichophyton agar 1 (casein) and 5 (niacin), harbored an ITS C-SNP, and a MAT1-1 mating type. Trichophyton equinum only grew on Trichophyton agar 5 (niacin), harbored an ITS T-SNP, and comprised of MAT1-2 mating type. The authors provide an impetus for future investigations by concluding 'evolution of $T$. tonsurans and $T$. equinum must be relatively recent, and speciation process might not yet be complete.' The tissue forms of Emmonsia species, pathogenic to small rodents and mustelids, resemble in vivo morphology of human pathogens Blastomyces and Histoplasma species. They share close morphological and genetic traits with other human pathogens in the Ajellomycetaceae family. After the recent re-classification of E. parva as $B$. parvus, it is important to define further the human and animal pathogenic species grouped in Ajellomycetaceae. However, the task is tough as an accurate estimate of Emmonsia species diversity, pathogenicity, and ecological range are difficult to obtain because their culture is quite problematic. Danesi et al. [30] worked on a solution for the diagnostic problem by designing a molecular survey using banked tissue specimens. The authors found 5\% positive samples in small burrowing animals. The successful DNA amplification from lung tissues included E. crescens, $B$. parvus, and Emmonsiellopsis species. The authors present detailed protocols for high-quality PCR amplifications of ITS and LSU genes from fresh and formalin-fixed paraffin-embedded lung tissues, thereby setting the stage for in-depth investigations of Emmonsia-like fungi. A disseminated case of Emergomyces pasteurianus in a 27 -year-old Indian AIDS patient further document the possible global occurrence of this newly discovered dimorphic pathogen. Capoor and colleagues [31] describe a well-documented case with characteristic microscopy, histopathology, ITS sequencing, dimorphic conversion, and excellent response to amphotericin B-itraconazole therapy. The authors also provide a timely review of published reports due to E. pasteurianus, E. europaeus, E. africanus, and E. canadensis. Durdu and colleagues [32] bring much needed understanding of the clinical condition Majocchi's granuloma (MG). The authors emphasize the term be exclusively used for the histopathological evidence of perifollicular granulomatous inflammation because of a dermatophyte. The recommendation is consistent with the original description of MG in 1883 by Prof. Domenico Majocchi. Additionally, Durdu et al. emphasize MG is predominantly a disease in immunocompetent patients. Thus, the description of the perifollicular granuloma due to non-dermatophyte pathogens in immunocompromised patients in several publications does not meet the classification criteria. The authors rightly emphasize such accuracy is a pre-requisite for appropriate treatment choice with terbinafine, which is not effective for non-dermatophytic fungi. A Mycopathologica IMAGE by Wei et al. [33] further expand the topic by highlighting features that help distinguish MG from Erythema Multiforme due to tinea of vellus.

The discoveries of new dimorphic pathogens are ripe for the perusal of an ambitious translational research agenda. More laboratory tools need to be developed, especially related to MALDI-TOF-MS spectra and PCR probes to assist laboratories in the rapid diagnosis. Similarly, it is incumbent upon the few specialized laboratories describing new species to make available an educational set of type materials of new species at low- or no-cost, so the examples of new pathogens are accessible at the frontline laboratories and do not remain confined to few specialized centers. As several new species were discovered retrospectively, it is crucial to expand the re-sampling to other fungal culture collections and archived paraffin tissues to get an accurate assessment of the prevalence of new pathogens as the cause of major fungal diseases. More focused training in modern fungal taxonomy and classification is needed for the clinical microbiologists 
and veterinary professionals to enlist them in search of as yet unknown onygenalean pathogens. Last, systematic investigations must begin to define the biological and pathological significance of new species.

\section{References}

1. Benny GL, Kimbrough JW. A synopsis of the orders and families of Plectomycetes with keys to genera. Mycotaxon. 1980;12(1):1-91.

2. Malloch D, Cain RF. New genera of Onygenaceae. Can J Bot. 1971;49(6):839-46.

3. von Arx J. A re-evaluation of the Eurotiales. Persoonia. 1987;13(Part 3):274-300.

4. Sugiyama M, Ohara A, Mikawa T. Molecular phylogeny of onygenalean fungi based on small subunit ribosomal DNA (SSU rDNA) sequences. Mycoscience. 1999;40(3):251-8.

5. Untereiner WA, Scott JA, Naveau FA, Sigler L, Bachewich J, Angus A. The Ajellomycetaceae, a new family of vertebrate-associated Onygenales. Mycologia. 2004;96(4):812-21.

6. Fisher MC, Koenig GL, White TJ, Taylor JW. Molecular and phenotypic description of Coccidioides posadasii $\mathrm{sp}$ nov., previously recognized as the non-California population of Coccidioides immitis. Mycologia. 2002;94(1):73-84.

7. Teixeira MdM, Theodoro RC, Oliveira FFMd, Machado GC, Hahn RC, Bagagli E, et al. Paracoccidioides lutzii sp. nov.: biological and clinical implications. Med Mycol. 2013;52(1):19-28.

8. Brown EM, McTaggart LR, Zhang SX, Low DE, Stevens DA, Richardson SE. Phylogenetic analysis reveals a cryptic Species Blastomyces gilchristii, sp. nov. within the human pathogenic fungus Blastomyces dermatitidis. PLoS ONE. 2013;8(3):e59237.

9. de Hoog GS, Dukik K, Monod M, Packeu A, Stubbe D, Hendrickx M, et al. Toward a novel multilocus phylogenetic taxonomy for the dermatophytes. Mycopathologia. 2017;182(1):5-31.

10. Schwartz IS, Wiederhold NP, Hanson KE, Patterson TF, Sigler L. Blastomyces helicus, a new dimorphic fungus causing fatal pulmonary and systemic disease in humans and animals in Western Canada and the United States. Clin Infect Dis. 2018;68(2):188-95.

11. Jiang Y, Dukik K, Muñoz JF, Sigler L, Schwartz IS, Govender NP, et al. Phylogeny, ecology and taxonomy of systemic pathogens and their relatives in Ajellomycetaceae (Onygenales): Blastomyces, Emergomyces, Emmonsia, Emmonsiellopsis. Fungal Divers. 2018;90(1):245-91.

12. Dukik K, Muñoz JF, Jiang Y, Feng P, Sigler L, Stielow JB, et al. Novel taxa of thermally dimorphic systemic pathogens in the Ajellomycetaceae (Onygenales). Mycoses. 2017;60(5):296-309.

13. Wang P, Kenyon C, de Hoog S, Guo L, Fan H, Liu H, et al. A novel dimorphic pathogen, Emergomyces orientalis
(Onygenales), agent of disseminated infection. Mycoses. 2017;60(5):310-9.

14. Herr RA, Tarcha EJ, Taborda PR, Taylor JW, Ajello L, Mendoza L. Phylogenetic analysis of Lacazia loboi places this previously uncharacterized pathogen within the dimorphic Onygenales. J Clin Microbiol. 2001;39(1):309-14.

15. Sepúlveda VE, Márquez R, Turissini DA, Goldman WE, Matute DR. Genome sequences reveal cryptic speciation in the human pathogen Histoplasma capsulatum. mBio. 2017;8(6):e01317-39.

16. Hoog S, Redhead S, Feng P, Jiang Y, Dukik K, Sigler L. (2465-2466) Proposals to conserve Blastomyces Gilchrist \& W. R. Stokes against Blastomyces Costantin \& Rolland and Ajellomycetaceae against Paracoccidioidaceae (Ascomycota: Onygenales). Taxon. 2016;65:1167-9.

17. Garcia HG, Yamauchi DH, Theodoro RC, Bagagli E. PRP8 intein in Onygenales: distribution and phylogenetic aspects. Mycopathologia. 2019. https://doi.org/10.1007/s11046019-00355-6.

18. Dukik K, de Hoog GS, Stielow JB, Freeke J, van den Ende BG, Vicente VA, et al. Molecular and phenotypic characterization of Nannizzia (Arthrodermataceae). Mycopathologia. 2019. https://doi.org/10.1007/s11046-01900336-9.

19. Packeu A, Stubbe D, Roesems S, Goens K, Van Rooij P, de Hoog S, et al. Lineages within the Trichophyton rubrum complex. Mycopathologia. 2019. https://doi.org/10.1007/ s11046-019-00386-z.

20. Metin B, Heitman J. She loves me, she loves me not: on the dualistic asexual/sexual nature of dermatophyte fungi. Mycopathologia. 2019. https://doi.org/10.1007/s11046019-00390-3.

21. Zheng H, Blechert O, Mei H, Ge L, Liu J, Tao Y, et al. Whole-genome resequencing of Trichophyton rubrum provides insights into population differentiation and drug resistance. Mycopathologia. 2019. https://doi.org/10.1007/ s11046-019-00384-1.

22. Kaplan E, Gonca S, Kandemir H, Döğen A, Hilmioğlu-Polat $\mathrm{S}$, Ilkit $\mathrm{M}$, et al. Genes encoding proteolytic enzymes fungalysin and subtilisin in dermatophytes of human and animal origin: a comparative study. Mycopathologia. 2019. https://doi.org/10.1007/s11046-019-00367-2.

23. Sharma R, Shouche YS. Diversity of onygenalean fungi in keratin-rich habitats of Maharashtra (India) and description of three novel taxa. Mycopathologia. 2019. https://doi.org/ 10.1007/s11046-019-00346-7.

24. Kollath DR, Teixeira MM, Funke A, Miller KJ, Barker BM. Investigating the role of animal burrows on the ecology and distribution of Coccidioides spp. in Arizona soils. Mycopathologia. 2019. https://doi.org/10.1007/s11046-01900391-2.

25. Hainsworth S, Hubka V, Lawrie AC, Carter D, Vanniasinkam T, Grando D. Predominance of Trichophyton interdigitale revealed in podiatric nail dust collections in Eastern Australia. Mycopathologia. 2019. https://doi.org/ 10.1007/s11046-019-00363-6.

26. Löpez Daneri G, Mujica MT. Frequency of the MatingType (MAT1) in Histoplasma capsulatum isolates from Buenos Aires, Argentina. Mycopathologia. 2019. https:// doi.org/10.1007/s11046-019-00402-2. 
27. Guerra BT, Almeida-Silva F, Almeida-Paes R, Basso RP, Bernardes JPRA, Almeida MA, et al. Histoplasmosis outbreaks in Brazil: lessons to learn about preventing exposure. Mycopathologia. 2019. https://doi.org/10.1007/s11046019-00389-w.

28. Baert F, Stubbe D, D'hooge E, Packeu A, Hendrickx M. Updating the taxonomy of dermatophytes of the BCCM/ IHEM Collection according to the new standard: a phylogenetic approach. Mycopathologia. 2019. https://doi.org/ 10.1007/s11046-019-00338-7.

29. Kandemir H, Dukik K, Hagen F, Ilkit M, Gräser Y, de Hoog GS. Polyphasic discrimination of Trichophyton tonsurans and T. equinum from humans and horses. Mycopathologia. 2019. https://doi.org/10.1007/s11046-019-00344-9.

30. Danesi P, Falcaro C, Dukik K, Jiang Y, Rizzoli AP, Allavena R, et al. Molecular diagnosis of Emmonsia-like fungi occurring in wild animals. Mycopathologia. 2019. https:// doi.org/10.1007/s11046-019-00353-8.

31. Capoor MR, Mishra N, Kolte S, Singla G, Gogna A, Rudramurthy S, et al. Disseminated Emergomyces pasteurianus infection in India: a case report and a review. Mycopathologia. 2019. https://doi.org/10.1007/s11046019-00387-y.

32. Durdu M, Kandemir H, Ilkit M, de Hoog GS. Changing concepts and current definition of Majocchi's granuloma.
Mycopathologia. 2019. https://doi.org/10.1007/s11046019-00358-3.

33. Wei F, Liang G, Liu W, Wang X, Sun J. Erythema multiforme associated with tinea of vellus hair caused by $\mathrm{Mi}$ crosporum canis. Mycopathologia. 2019. https://doi.org/10. 1007/s11046-019-00409-9.

34. Dukik K, Al-Hatmi AMS, Curfs-Breuker I, Faro D, de Hoog $\mathrm{S}$, Meis JF. Antifungal susceptibility of emerging dimorphic pathogens in the family Ajellomycetaceae. Antimicrob Agents Ch. 2018;62(1):e018817-86.

35. de Almeida JN, Del Negro GM, Grenfell RC, Vidal MS, Thomaz DY, de Figueiredo DS, et al. MALDI-Tof mass spectrometry for rapid identification of the dimorphic fungi Paracoccidioides brasiliensis and Paracoccidioides lutzii. J Clin Microbiol. 2015;53:1383-6.

36. Ramani R, Chaturvedi V. Antifungal susceptibility profiles of Coccidioides immitis and Coccidioides posadasii from endemic and non-endemic areas. Mycopathologia. 2007;163(6):315-9.

Publisher's Note Springer Nature remains neutral with regard to jurisdictional claims in published maps and institutional affiliations. 